\title{
Stage IV Cervical Cancer AJCC v6 and v7
}

National Cancer Institute

\section{Source}

National Cancer Institute. Stage IV Cervical Cancer A/CC v6 and v7. NCI Thesaurus. Code C9206.

Stage IV includes: IVA: (T4, Any N, M0); IVB (Any T, Any N, MI). T4: Tumor invades mucosa of bladder or rectum, and/or extends beyond true pelvis (bullous edema is not sufficient to classify a tumor as T4). M1: Distant metastasis. (AJCC 6th and 7th eds.) 